\title{
〔原著論文〕HLA-B35 and MICA-A5 synergistically enhanced the susceptibility to Chagas heart disease
}

\author{
Kayano Aida'), Sandra Juarez ${ }^{1}$, Mihoko Kikuchii", Martin Gil ${ }^{122}$, \\ Oscar Ayau ${ }^{3}$, Maria Paula De Lopes ${ }^{122}$, Satoshi Kaneko4, \\ Tetsuo Yanagi ${ }^{5}$, Tamara Obispo'), Edmundo Velasque ${ }^{11}$, \\ Mu Jianbing ${ }^{1)}$, Vivian Matta ${ }^{2}$, Margarita $\mathrm{Paz}^{2}$, Akinori Kimura ${ }^{6}$, \\ Kyogo Itoh $^{7)}$, Isao Tada ${ }^{8)}$ and Kenji Hirayama ${ }^{1)}$
}

\begin{tabular}{|}
${ }^{1)}$ Department of Medical Zoology, Saitama Medical School, Saitama, Japan \\
${ }^{2)}$ Facultad de Ciencias Quimicas y Farmacia, Universidad de San Carlos, Guatemala City, Guatemala \\
${ }^{3)}$ Departament de Cardiologia del Hospital Nacional de Zacapa, Zacapa, Guatemala \\
${ }^{4)}$ Mision Japonesa, Agencia de cooperacion International del Japon, Guatemala City, Guatemala \\
${ }^{5)}$ Department of Protozoology, Institute of Tropical Medicine, Nagasaki University, Nagasaki, Japan \\
${ }^{6)}$ Department of Molecular Pathogenesis, Division of Adult Disease, Medical \\
Research Institute, Tokyo Medical and Dental University, Tokyo, Japan \\
${ }^{7)}$ Department of Immunology, Faculty of Medicine, Kurume University, Fukuoka, Japan \\
${ }^{8)}$ Department of Parasitology, Faculty of Medicine, Kyushu University, Fukuoka, Japan
\end{tabular}

(Received March 13, 2000)

\section{Introduction}

Chagas disease, caused by the protozoan parasite Trypanosoma cruzi (T. cruzi), is a major public health problem in Central and South America (1). An epidemiological study in an endemic area, Guatemala, showed that, on average, $5-10 \%$ of the individuals were seropositive and considered to be persistently infected with $T$. cruzi (2). Five to 30 years after primary infection, about $30 \%$ of the seropositive individuals develop heart disease which is characterized by electrocardiographic alterations, heart failure, or sudden death, and has been suggested to be one of the major causes of death in this endemic area. The other $70 \%$ of seropositive individuals remain asymptomatic. In Guatemala, there are no chronic patient with digestive disorders such as megacolon, although this has been reported in other populations (1).

We are currently unable to predict whether exposed individuals will eliminate the organism or develop chronic Chagas disease. The natural course of infection in humans remains unclear, although there is little epidemiological information such as incidence, cure rate, force of infection and death rate. In an experimental mouse model system, previous studies have elegantly showed that $\mathrm{CD} 8+$ cytotoxic $\mathrm{T}$ cells are essential for elimination of the parasite $(3,4,5)$. Recently, Widel et al. showed that specific $\mathrm{CD} 8^{+} \mathrm{T}$ cells were also active in human Chagas patients in Guatemala (6). Autoimmune mechanisms have been reported to play an important role in the development of chronic Chagas heart disease, both in an experimental mouse model and in humans (7, 8, 9, 10). However, the pathogenic process by which chronic Chagas disease develops is still controversial (11).

Because immune response has been suggested to play a role both in the control of susceptibility to $T$. cruzi infection and in the development of chronic disease, genetic predisposition of the host may influence the outcome of the infection $(12,13)$. To determine the host genetic factors that influence susceptibility to Chagas heart disease, we typed cardiac Chagas patients for polymorphisms of the closely linked genes HLA-B, MICA and the TNF-a promoter region, and identified
Corresponding author ;K.Hirayama, M.D.,

Department of Medical Zoology, Saitama Medical School, Moroyama, Saitama 350-0495, Japan.
Telephone: 0492-76-1172, Fax: 0492-94-2274,

E-mail: hiraken@saitama-med.ac.jp 
HLA-B35 and MICA-A5 as two major markers of the susceptibility.

\section{Materials and Methods}

Subjects. Typing for HLA-B, the TM region of MICA and TNF promoter region polymorphisms was performed on 33 unrelated, seropositive Chagas patients (11 men and 22 women, mean age 60.8 years) with heart problem, including 29 with typical electrocardiograph abnormalities such as ventricular conduction defects, atrioventricular block and atrial fibrillation described by Kawabata et al.(14) and Maguire et al. (15), and 4 with hypertrophy of heart in their chest $\mathrm{X}$ rays but without any ECG abnormalities. They were outpatients at the Department of Cardiology, Zacapa National Hospital, Zacapa, Guatemala. 138 seronegative healthy controls (46 men and 92 women, mean age 38.1 years) were also typed. The subjects were mestisos, all from Zacapa or surrounding areas, and the geographical distribution of their residences was similar between patient and control groups. The serological diagnosis of Chagas disease was performed by indirect haemagglutination test (1) or immuno-double diffusion test (1) and in all cases by enzyme-linked immunosorbent assay for anti-T. cruzi $\operatorname{Ig} G_{1}(1)$.

DNA extraction. Genomic DNA was extracted from peripheral blood using a kit (DNA Extractor WB, Wako Pure Chemicals, Osaka, Japan) as previously described (16).

HLA-B typing. HLA-B typing by sequence specific oligonucleotide probe (SSOP) method was carried out following the protocol described by Yoshida et al. (17). Exon 2 of the HLA-B gene was amplified by polymerase chain reaction (PCR). Labeled SSO probes were hybridized with amplified DNA on nylon membrane and detected by the chemiluminescent method (17).

MICA typing. We analyzed the TM region

Table 1.

(a) The frequencies of HLA-B in the patients with Chagas disease and healthy controls.

\begin{tabular}{|c|c|c|c|c|c|}
\hline $\mathrm{ECBa}$ & $\begin{array}{r}\text { Chagas } \\
\text { patients } \\
\mathrm{n}=33(\%)\end{array}$ & $\begin{array}{l}\text { Healthy } \\
\text { controls } \\
\qquad \mathrm{n}=138(\%)\end{array}$ & $\mathrm{P}$ & $\mathrm{Pc}$ & OR $(95 \% \mathrm{CI})$ \\
\hline B0703 & $3(9.1)$ & $1 \quad(0.7)$ & & & \\
\hline B0801 & $11(33.3)$ & $28 \quad(20.3)$ & & & \\
\hline B13 & $0(0)$ & $1(0.7)$ & & & \\
\hline B15 & $4(12.1)$ & $0 \quad(0)$ & & & \\
\hline B1524 & $0(0)$ & $4(2.9)$ & & & \\
\hline B $1801 / 1802$ & $0 \quad(\quad 0)$ & $5(3.6)$ & & & \\
\hline B27 & $0(0)$ & $3(2.2)$ & & & \\
\hline B2708 & $1(3.0)$ & $0 \quad\left(\begin{array}{l}0 \\
0\end{array}\right.$ & & & \\
\hline B35 & $25(75.8)$ & $50(36.2)$ & $<0.0001$ & $<0.003$ & $5.50(2.31-13.11)$ \\
\hline B3801/1523 & $0 \quad(0)$ & $3(2.2)$ & & & \\
\hline B39 & $2(6.1)$ & $2(1.4)$ & & & \\
\hline B3902 & $0 \quad(0)$ & $4(2.9)$ & & & \\
\hline B40 & $5(15.2)$ & $45 \quad(32.6)$ & 0.0476 & 1.333 & $0.37(0.13-1.02)$ \\
\hline B41 & $0 \quad(0)$ & $1(0.7)$ & & & \\
\hline B44 & $1(3.0)$ & $9(6.5)$ & & & \\
\hline B4701 & $0\left(\begin{array}{l}0 \\
0\end{array}\right.$ & $3(2.2)$ & & & \\
\hline B48 & $1(3.0)$ & $3(2.2)$ & & & \\
\hline B4901 & $1(3.0)$ & $15(10.9)$ & & & \\
\hline B4902 & $0 \quad(\quad 0)$ & $1(0.7)$ & & & \\
\hline B51 & $1(3.0)$ & $12(8.7)$ & & & \\
\hline В5201 & $4(12.1)$ & $3(2.2)$ & & & \\
\hline B55 & $\begin{array}{ll}0 & 0\end{array}$ & $13(9.4)$ & & & \\
\hline B57 & 2 ( 6.1$)$ & $15(10.9)$ & & & \\
\hline B58 & $1 \quad(3.0)$ & $5(3.6)$ & & & \\
\hline B5901 & $0(0)$ & $4(2.9)$ & & & \\
\hline B62 & $0(0)$ & $5(3.6)$ & & & \\
\hline B7301 & $2(6.1)$ & $0 \quad(0)$ & & & \\
\hline B7801 & $2(6.1)$ & $10(7.2)$ & & & \\
\hline
\end{tabular}


polymorphism of the MICA gene using the PCR-singlestrand conformation polymorphism (SSCP) method (18). PCR amplification was performed by the method described by Mizuki et al. (19). Briefly, a total volume of $30 \mathrm{ml}$ of amplification reaction mixture contained $100 \mathrm{ng}$ of template DNA, $10 \mathrm{mM}$ Tris- $\mathrm{HCl}$ (pH8.3), $50 \mathrm{mM} \mathrm{KCl}, 2.5 \mathrm{mM} \mathrm{MgCl}_{2}, 0.25 \mathrm{U}$ Ampli Taq DNA polymerase (Perkin Elmer, NJ, USA), $0.2 \mathrm{mM}$ dNTPs, $5 \mathrm{pM}$ of $5^{\prime}$ primer (MICA5F; 5'CCTTTTTTTCAGGGAAAGTGC-3') and $3^{\prime}$ primer (MICA5R; 5'-CCTTACCATCTCCAGAAACTGC-3'). PCR was performed under the following conditions: denaturing at $95{ }^{\circ} \mathrm{C}$ for $9 \mathrm{~min}$, followed by 38 cycles of denaturing at $94{ }^{\circ} \mathrm{C}$ for $15 \mathrm{sec}$, annealing at $56{ }^{\circ} \mathrm{C}$ for $15 \mathrm{sec}$, extension at $72{ }^{\circ} \mathrm{C}$ for $45 \mathrm{sec}$, and a final extension at $60{ }^{\circ} \mathrm{C}$ for $20 \mathrm{~min}$. Heat-denatured PCR products with 2 volumes of formamide dye $(88 \%$ formamide, $10 \mathrm{mM}$ EDTA, $0.01 \%$ bromphenol blue, $0.01 \%$ xylene cyanol) were loaded on a $14 \mathrm{~cm} \mathrm{X} 14 \mathrm{~cm}$ $\mathrm{X} 1 \mathrm{~mm}$ polyacrylamide gel ( $7 \%$ acrylamide, $0.4 \mathrm{XTBE}$, $10 \%$ glycerol) and run at constant voltage (10 volt / cm) under a constant temperature of $26{ }^{\circ} \mathrm{C}$. DNA fragments were visualized by silver staining (Silver Stain kit II, Wako Pure Chemicals, Osaka, Japan). We compared SSCP patterns of the samples with those of the homozygous B cell lines (BM92, OLGA, BM14, HHKB, RML, AMAL) whose MICA types have been well established (19).

TNF promoter region polymorphism. Polymorphisms of the TNF-a promoter region were analyzed by the SSOP method described by Higuchi et al. (20). The $1051 \mathrm{bp}$ sequence of the TNF-a gene at position -1236 to -186 was amplified by PCR method with 5 ' primer (5'-
GGGGACACACAAGCATCAAGG-3') and 3' primer (5'-GCTGTCTGCTTGTGTGTGTGTGTCTGGG-3') under the following conditions: denaturing at $95{ }^{\circ} \mathrm{C}$ for $3 \mathrm{~min}$ and extension at $72^{\circ} \mathrm{C}$ for $5 \mathrm{~min}$, followed by 35 cycles of denaturing at $94{ }^{\circ} \mathrm{C}$ for $1 \mathrm{~min}$, annealing at 60 oC for $2 \mathrm{~min}$, extension at $72{ }^{\circ} \mathrm{C}$ for $3 \mathrm{~min}$, and a final extension at $72{ }^{\circ} \mathrm{C}$ for $10 \mathrm{~min}$. The PCR product was blotted on nylon membrane and hybridized with 10 different probes to identify the following dimorphic sites, $-238 \mathrm{G} / \mathrm{A},-308 \mathrm{G} / \mathrm{A},-857 \mathrm{C} / \mathrm{T},-863 \mathrm{C} / \mathrm{A}$, 1031T/C, as described (20).

Statistical analyses. We compared the allele frequencies of HLA-B, TM region of MICA and TNF-a promoter region between Chagas patients and seronegative healthy controls by the chi-squared test (21). The obtained Pvalue was corrected by the Bonferroni correction (22), multiplication by the number of the alleles tested $(\mathrm{Pc})$. The observed difference was considered statistically significant when $\mathrm{Pc}$ was less than 0.05. Odd's ratio (OR) and $95 \%$ confidence interval (CI) were estimated to analyze the risk for the disease (23). The method of Mittal (24) was used for the linkage analysis among HLA-B, MICA and TNF-a promoter alleles. When the $\mathrm{t}$-value was greater than 2.0 , linkage disequilibrium (LD) was considered to be present.

\section{Results}

HLA-B typing. Twenty-eight epitope combination groups of HLA-B (ECB) were detected in the subjects. $75.8 \%$ of the patients were typed as HLA-B 35, compared to only $36.2 \%$ of the controls. The frequency of HLA-B35 was significantly increased in the patients $\left(\mathrm{X}^{2}=16.90, \mathrm{Pc}<0.003, \mathrm{OR}=5.50,95 \% \mathrm{CI}=2.31\right.$ -

Table 1.

(b) Frequencies of the MICA alleles in patients with Chagas disease and healthy controls.

\begin{tabular}{lrllll}
\hline MICAb & $\begin{array}{l}\text { Chagas } \\
\text { patients } \\
\mathrm{n}=32(\%)\end{array}$ & $\begin{array}{l}\text { Healthy } \\
\text { controls } \\
\mathrm{n}=134(\%)\end{array}$ & P & Pc & OR (95\%CI) \\
\hline A4 & $5(15.6)$ & $22(15.9)$ & & & \\
A5 & $13(40.6)$ & $40(29.9)$ & 0.240 & 1.200 & $1.61(0.72-3.57)$ \\
A5.1 & $5(15.6)$ & $29(21.0)$ & & & \\
A6 & $6(18.8)$ & $48(35.8)$ & 0.064 & 0.320 & $0.41(0.16-1.07)$ \\
A9 & $24(75.0)$ & $96(71.6)$ & & & \\
\hline
\end{tabular}

b: MICA; MHC class I chain related gene A. MICA alleles are determined by using the microsatellites polymorphism in the MICA TM region (exon 5). Terminology of the alleles are derived from Mizuki et al. (19). 


\subsection{1) (Table 1a).}

MICA typing. Five alleles of MICA previously reported in TM region (19) were typed in Guatemalan subjects (Table 1b). The frequency of MICA-A5 was increased in the patients compared with controls. However, the differences was not significant $\left(\mathrm{X}^{2}=1.38, \mathrm{P}=0.240\right.$, $\mathrm{Pc}=1.200$ ) (Table 1b).

Haplotype analysis. There were three HLA-B-MICA combinations with positive LD, HLA-B35-MICA-A9, HLA-B55-MICA-A5.1 and HLA-B4901-MICA-A6. T-values were calculated using Mittal's method (24) to be $5.61,2.79$ and 2.26 , respectively (Table 2). HLA-

\section{Table 2.}

Linkage disequilibrium between ECB and MICA alleles

\begin{tabular}{lccc}
\hline \multicolumn{4}{c}{ HLA-B } \\
MICA & 35 & 55 & 4901 \\
\hline MICA-A5 & - & - & - \\
MICA-A5.1 & - & $2.79 \mathrm{a}$ & - \\
MICA-A6 & - & & 2.26 \\
MICA-A9 & 5.61 & - & - \\
\hline
\end{tabular}

a: $t$-value was calculated by the method of Mittal (24). A t-value of more than 2.0 indicates a positive linkage disequilbrium. The indication of negative (-) means the $\mathrm{t}$-value was less than 2.0 .

B35-MICA-A9 haplotype was significantly increased in the patients $\left(\mathrm{X}^{2}=10.51, \mathrm{P}=0.0012, \mathrm{OR}=3.65\right.$, $95 \% \mathrm{Cl}=1.62-8.23$ ) (data not shown). However, those associations may be due to the strong association between HLA-B35 and the disease, because MICA-A9 itself did not show any significant association as noted above. Although both HLA-B35 and MICA-A5 were increased in the seropositive patients, there was no significant LD between these two alleles.

To analyze the effects of HLA-B35 and MICA-A5 on the susceptibility, we classified the subjects into four groups according to their HLA-B and MICA markers: both HLA-B35 and MICA-A5 negative (B35 / A5), HLA-B35 positive and MICA-A5 negative (B35+ / A5 ), HLA-B35 negative and MICA-A5 positive (B35 / A $5^{+}$), and both HLA-B 35 and MICA-A 5 positive individuals $\left(\mathrm{B} 35^{+} / \mathrm{A} 5^{+}\right)$(Table 3$)$. The patients were observed at a greater rate in group $\mathrm{B} 35+/ \mathrm{A} 5+$ than in group $\mathrm{B} 35+/ \mathrm{A} 5-\left(\mathrm{X}^{2}=3.86, \mathrm{P}=0.0495, \mathrm{OR}=2.86\right.$, $95 \% \mathrm{Cl}=0.98-8.31$ ), while there was no difference between group B35-/ A5+ and group B35- / A5- $\left(\mathrm{X}^{2}=\right.$ $0.01, \mathrm{P}=0.920, \mathrm{OR}=1.08,95 \% \mathrm{Cl}=0.24-4.84)$. Therefore, the effects of MICA-A5 on susceptibility to infection with $\mathrm{T}$. cruzi appeared only in the presence of HLA-B35. As shown in Table 3, increased risk for the individuals who had both HLA-B35 and MICA-A5 (OR B35/A5-1 = 9.80) was much higher than the sum of the increased risks $((\mathrm{OR} B 35-1)+(\mathrm{OR} A 5-1)=2.86)$ for either HLA-B 35 alone or MICA-A5 alone positive individuals, showing that the effects of HLA-B35 and MICA-A5 on the susceptibility were synergistic.

TNF-a promoter typing. Located within $300 \mathrm{~kb}$ on the centromeric side of the MICA and HLA-B genes, are genes for two other potentially important regulators of protective immunity, TNF-a and b. To clarify whether the susceptibility effect of HLA-B35 and MICA-A5 was due to the HLA-B and MICA genes themselves or to reflection of $L D$ between these markers with the polymorphisms in the TNF region, TNF-a promoter polymorphisms were analyzed in the Guatemalan subjects. There was, however, no association between dimorphisms at any of the five positions (-238, -308, $857,-863,-1031)$ in TNF-a promoter region polymorphism and seropositivity (data not shown).

\section{Discussion}

Using knockout mice, Tarleton et al. have shown that

Table 3.

Odd ts ratio of each combination of HLA-B35 and MICA-A5

\begin{tabular}{ccccr}
\hline & & $\begin{array}{c}\text { Chagas } \\
\text { patients } \\
\text { HLA-B35 }\end{array}$ & $\begin{array}{l}\text { Healthy } \\
\text { controls } \\
\mathrm{n}=32\end{array}$ & $\mathrm{n}=134$ \\
\hline- & - & 5 & 54 & ORa \\
- & + & 3 & 30 & 1.08 \\
+ & - & 14 & 40 & 3.78 \\
+ & + & 10 & 10 & 10.80 \\
\hline
\end{tabular}

a: OR was calculated against individuals negative both HLA-B35 and MICA-A5 
both $\mathrm{CD} 4^{+}$and $\mathrm{CD} 8{ }^{+} \mathrm{T}$ cells stimulated by HLA-class II and class I, respectively, were essential in the protective immunity against $T$. cruzi infection (3). CD $8+\mathrm{T}$ cells isolated from mice chronically infected with $T$. cruzi expressed MHC restricted cytolytic activity against infected macrophages (4). Anti-CD8 antibody treatment increased susceptibility to $T$. cruzi in the resistant C57BL/6J mice (5). These studies suggest that the $\mathrm{CD} 8^{+} \mathrm{T}$ cell subset is important in immunity against $T$. cruzi in mice. In the present study, we found an association between HLA-B 35 and Chagas heart disease, suggesting that $\mathrm{CD} 8^{+} \mathrm{T}$ cells restricted by $\mathrm{MHC}$ class I molucules may play an important role in immunity to T. cruzi, not only in mice, but also in humans. Althougth we did not check HLA-A type in the subjects, Indeed, Wizel et al. recently reported that HLAA 2 binding antigenic peptides stimulated the patients' CTL (6).

After the identification of HLA-B35 as a marker of susceptibility, we analyzed the neighboring HLA class Ilike gene, MICA, and found another significant susceptible combination of HLA-B35 and MICA-A5, which was not derived from LD between these two markers. The effect of these was not additive, but synergistic, as shown in Table 3. MICA is similar in structure to mouse MHC class Ib (TL region), which can be recognized by $\gamma \delta$ T cells $(25,26,27)$. Groh et al. demonstrated that MICA can be expressed in TAPnegative cells, suggesting that its expression is independent of peptide binding (28). They also reported that $\gamma \delta \mathrm{T}$ cells bearing $\mathrm{V} \delta 1 \mathrm{TCR}$ from intestinal epithelium were stimulated by MICA and MICB (29). $\mathrm{V} \delta 1 \gamma \delta \mathrm{T}$ cells represent 70 to $90 \%$ of the $\gamma \delta \mathrm{T}$ cells in the intestinal epithelium that maintain the integrity of the gut epithelium by eliminating infected or damaged epithelial cells. These activated $\mathrm{T}$ cells may possibly be recruited to other damaged tissues where MICA is positive.

Because the effects of HLA-B35 and MICA-A5 on the susceptibility were synergistic, susceptibility is likely determined by an interaction between activated $\mathrm{T}$ cells stimurated by the MICA molecule and by the MHC class I, although there is always the possibility that other closely linked susceptibility genes may been involved. With regards to HLA-B35, susceptibility associations have also been observed with subacute thyroiditis (30) and AIDS (31, 32). The common mechanisms underlining these associations should be an important subject of analysis.

Because TNF genes are located close to the MICA gene, the MICA-A5 effect might have been observed if there were any LD with some susceptibility allele of the TNF-a promoter region, which controls the transcriptional level of TNF-a (33). However, there was no association between TNF-a promoter type and susceptibility to Chagas disease, and no LD between TNF-a promoter and MICA type polymorphisms, indicating that the effect on the susceptibility and MICAA5 was not due to LD between the TNF-a promoter and MICA.

The pathogenesis of Chagas heart disease in the chronic phase remains unknown. It has been suggested that some autoimmune mechanisms may result in damage to the heart $(7,8,9,10)$. Cunha-Neto et al. demonstrated that chronic Chagas patients with heart disease had $T$. cruzi -cardiac myosin cross reactive autoantibody in their sera (9). Santos et al. reported that anti-CD4 monoclonal antibodies abrogated the rejection of syngeneic newborn heart grafts in chronically infected mice, and that $\mathrm{CD} 4{ }^{+} \mathrm{T}$ cells from chronically infected mice showed a proliferative response to syngeneic myocardium antigens (34). These reports suggest that autoimmunity is involved in the pathogenesis of Chagas heart disease, and that $\mathrm{CD} 4^{+} \mathrm{T}$ cells play an important role. However, there is no report that clearly described the association between HLA-class II antigens and Chagas heart disease. In this study, we also typed for their HLA-DR, DQ and DP and found no significant association (data not shown). Llop et al. reported that HLA-B40-Cw3 haplotype was significantly decreased in cardiac Chagas patients compared with non-cardiac patients, indicating this haplotype associates with resistance (12). In the present study, we also observed a decreased frequency of HLA-B40 in the cardiac Chagas patients $(15.2 \%)$ than in the controls $(32.6 \%)$, although it was not statistically significant after Bonferroni correction ( $\mathrm{P}=0.0476, \mathrm{Pc}=1.333$ ) (Table 1a). But if we consider the previous study (12) as the first finding of resistant HLA-B40, it may not necessary to correct our results by Bonferroni and we may claim that the frequency of HLA-B40 decreased in Chagas heart disease. The observations that HLA-class I rather than class II associated with Chagas heart disease suggest that the deterioration of the disease is partially caused by 
insufficient elimination of the parasites due to decreased activity of immunity. In conclusion, we found that HLAB35 and MICA-A5 increased the risk for developing Chagas heart disease, and that the effects of the two alleles on susceptibility were synergistic.

\section{Acknowledgments}

We are grateful to Drs. K. Ogata, and Y. Tabaru, Regional Heads of the JICA project in Guatemala, Dr. O. Ochoa, SNEM, Ministry of Health of Guatemala, Prof. C. Monroy, and A. Caceres, San Carlos University, for their kind help in performing field work in Guatemala, and to Dr. A. Shimada and I. Morimoto, Nagasaki University for their helpful discussions.

This work was supported by a Grant for International Health cooperation Research (9C-3, 5C-6) from Ministry of Health and Welfare and in part by JICA, Japan International Cooperation Agency (GJET-141)

\section{References}

1. World Health Organization expert commitee. Control of Chagas disease. Geneva: World Health Organization. 1991.

2. Velasquez EG, Yamashita K, Morimoto I, et al. : Epidemiological survey of Chagas disease in a rural area of Guatemala; an association of ECG abnormalities with seropositivity to Trypanosoma cruzi. Jpn. J. Trop. Med. Hyg. 24 : 107-112, 1996.

3. Tarleton RL, Grusby MJ, Postan M, et al. :

Trypanosoma cruzi infection in MHC-deficient mice: further evidence for the role of both class I- and class II-restricted $\mathrm{T}$ cells in immune resistance and disease. Int. Immunol. 8 : 13-22, 1995.

4. Nickell SP, Stryker GA, Arevalo C: Isolation from Trypanosoma cruzi-infected mice of $\mathrm{CD} 8+$, MHCrestricted cytotoxic $\mathrm{T}$ cells that lyse parasite-infected target cells. J. Immunol. 150 : 1446-1457, 1993.

5. Tarleton RL: Depletion of CD8+ T cells increases susceptibility and reverses vaccine induced immunity in mice infected with Trypanosoma cruzi. J. Immunol .144 : 717-724, 1990.

6. Wizel B, Palmieri M, Mendoza C, et al.:Human infection with Trypanosoma cruzi induces parasite antigen-specific cytotoxic T lymphocyte responses. $J$.
Clin. Invest. 102: 1062-1071, 1998.

7. Levin MJ, Kaplan D, Ferrari I, et al.: Humoral autoimmune response in Chagas' disease: Trypanosoma cruzi ribosomal antigens as immunizing agents. FEMS Immunol. Med. Microbiol. 7 : 205210, 1993.

8. Levin MJ, Mesri E, Benarous R, et al.: Identification of major Trypanosoma cruzi antigenic determinants in chronic Chagas' heart disease. Am. J. Trop. Med. Hyg. 41 : 530-538, 1989.

9. Cunha-Neto E, Duranti M, Gruber A, et al.: Autoimmunity in Chagas disease cardiopathy: biological relevance of cardiac myosin-specific epitope cross reactive to an immunodominant Trypanosoma cruzi antigen. Proc. Natl. Acad. Sci .USA 92 : 3541-3545, 1995.

10. Kierszenbaum F: Autoimmunity in Chagas' disease. J. Parasitol. 72 : 201-211, 1986.

11. Tarleton RL, Zhang L Downs MO: "Autoimmune rejection" of neonatal heart transplants in experimental Chagas disease is a parasite specific response to infected host tissue. Proc. Natl. Acad. Sci. USA 94 : 3932-3937, 1997.

12. Llop E, Rothhammer F, Acuna M, et al::HLA antigens in Cardiomyopathic Chilean Chagasics. Am. J. Hum. Genet. 43 : 770-773, 1988.

13. Fernandes-Mestre MT, Layrisse Z, Montagnani S, et al.: Influence of the HLA class II polymorphism in chronic Chagas' disease. Parasite Immunol. 20 : 197 203, 1998.

14. Kawabata M, Uchiyama $\mathrm{T}$, Mimori $\mathrm{T}$, et al. : Association of electrocardiographic abnormalities with seropositivity to Trypanosoma cruzi in Ecuador. Trans. R. Soc. Trop. Med. Hyg. 81 : 7-10, 1987.

15. Maguire JH, Mott KE, Lehman JS, et al.: Relationship of electrocardiographic abnormalities and seropositivity to Trypanosoma cruzi within a rural community in Northeast Brazil. Am. Heart. J. 105 : 287-294, 1983.

16. Hirayama K, Zaidi ASM, Lokman Hakim S, et al.: Molecular analysis of HLA-B in the Malaysian 
aborigines. Tissue Antigens. 48 : 692-697, 1996.

17. Yoshida M, Kimura A, Numao F, et al.: Polymerase-Chain-Reaction-baced analysis of polymorphism in the HLA-B gene. Hum. Immunol.34 : 257-266, 1992.

18. Kimura A, Hoshino S, Yoshida M, et al.: HLA 1991 volume 1. Proceedings of the Eleventh International Histocompatibility Workshop and Conference (eds. Aizawa M, Sasazuki T), Polymerase chain reaction-single strand conformation polymorphism (PCR-SSCP) analysis. Oxford University Press,New York, 1992; p.511-514.

19. Mizuki N, Ota M, Kimura M, et al.: Triplet repeat polymorphism in the transmembrane region of the MICA gene: A strong association of six GCT repetitions with Behcet disease. Proc. Natl. Acad. Sci. USA 94 : 1298-1303, 1997.

20. Higuchi T, Seki N, Kamizono S, et al.:

Polymorphism of the 5 '-flanking region of human tumor necrosis factor (TNF) -a gene in Japanese. Tissue Antigens 51 : 605-612, 1998.

21. Dyer P, Warrens A: Design and interpretation of studies of the major histocompatibility complex in disease. ed Lechler R, HLA \& disease. London: Academic press, 93-121, 1994.

22. Tukey JM. Some thoughts on clinical trials, especially problems of multiplicity. Science 198 : 679-698, 1977.

23. Morris JA, Gardner MJ. Calculating confidence interval for relative risk (odds ratios) and standard rates. Brit Med. J. 296 : 1313-1316, 1988.

24. Mittal KK: The HLA polymorphism and susceptibility to disease. Vox. Sang. 31 : 161-173, 1976.

25. Itoh $\mathrm{K}$, Van Kaer L, Bonneville M, et al.:

Recognition of the product of a novel MHC TL region gene (27b) by a mouse gd $\mathrm{T}$ cell receptor. Cell 62 :
549-561, 1990.

26. Schild H, Mavaddat N, Litzenberger C, et al.: The nature of major histocompatibility complex recognition by $\gamma \delta$ T cells. Cell $76: 29-37,1994$.

27. Kaliyaperumal A, Falchetto R, Cox A, et al.: Functional expression and recognition of nonclassical MHC class I T10b is not peptidedependent. $J$. Immunol. 155 : 2379-86, 1995.

28. Groh V, Bahram S, Bauer S, et al:: Cell stressregulated human major histocompatibility complex class I gene expressed in gastrointestinal epithelium. Proc. Natl. Acad. Sci. USA. 93 : 12445-12450, 1996.

29. Groh V, Steinle A, Bauer S, et al:: Recognition of stress-induced MHC molecules by intestinal epithelial gd Tcells. Science 279 : 1737-1740, 1998.

30. Ohsako N, Tamai H, Sudo T, et al:: Clinical characteristics of subacute thyroiditis classified according to human leukocyte antigen typing. J. Clin .Endocrinol. Metab. 80 : 3653-3656, 1995.

31. Carrington M, Nelson GW, Martin MP, et al.: HLA and HIV-1:Heterozygote advantage and B35Cw04 disadvantage. Science 283 : 1748-1752, 1999.

32. Just JJ: Genetic predisposition to HIV-1 infection and acquired immune deficiency virus syndrome: a review of the literature examining associations with HLA. Hum. Immunol 44 : 156-169, 1995.

33. Kern P, Hemmer CJ, Van Damme J, et al.: Elevated tumor necrosis factor alpha and interleukin- 6 serum levels as markers for complicated Plasmodium falciparum malaria. Am. J. Med 87: 139-143, 1989.

34. Ribeiro dos Santos R, Rossi MA, Laus JL, et al. : Anti CD4 abrogates rejection and reestablishes longterm tolerance to syngeneic newborn hearts grafted in mice chronically infected with Trypanosoma cruzi. $J$. Exp. Med. 175 : 29-39, 1992. 


\section{HLA-B35 and MICA-A5 synergistically enhanced the susceptibility to Chagas heart disease}

Kayano Aida ${ }^{1)}$, Sandra Juarez ${ }^{1}$, Mihoko Kikuchi ${ }^{1}$, Martin Gil ${ }^{122}$, Oscar $\mathrm{Ayau}^{31}$, Maria Paula De Lopes ${ }^{122}$, Satoshi Kaneko ${ }^{4)}$, Tetsuo Yanagi ${ }^{5)}$, Tamara Obispo ${ }^{4)}$, Edmundo Velasquez ${ }^{4)}$, Mu Jianbing ${ }^{1}$, Vivian Matta ${ }^{2}$, Margarita Paz ${ }^{2}$, Akinori Kimura ${ }^{6}$, Kyogo Itoh ${ }^{7)}$, Isao Tada ${ }^{8)}$ and Kenji Hirayama ${ }^{1)}$

1) Department of Medical Zoology, Saitama Medical School, Moroyama, Saitama, Japan

2) Facultad de Ciencias Quimicas y Farmacia, Universidad de San Carlos, Guatemala City, Guatemala

3) Departament de Cardiologia del Hospital Nacional de Zacapa, Zacapa, Guatemala

4) Mision Japonesa, Agencia de cooperacion International del Japon, Guatemala City, Guatemala

5) Department of Protozoology, Institute of Tropical Medicine, Nagasaki University, Sakamoto, Nagasaki, Japan

6) Department of Molecular Pathogenesis, Division of Adult Disease, Medical Research Institute, Tokyo Medical and Dental University, Tokyo, Japan

7) Department of Immunology, Faculty of Medicine, Kurume University, Kurume, Fukuoka, Japan

8) Department of Parasitology, Faculty of Medicine, Kyushu University, Maidashi, Higashi-ku, Fukuoka, Japan Correspondence should be addressed to K.Hirayama, M.D., Department of Medical Zoology, Saitama Medical School, Moroyama, Saitama 350-0495, Japan.

Telephone: 0492-76-1172, Fax: 0492-94-2274,

E-mail: hiraken@saitama-med.ac.jp

\section{Summary}

To determine the host genetic factors that influence susceptibility to Chagas heart disease, we typed 33 unrelated, seropositive Chagas patients with cardiac disorders at the Department of Cardiology, Zacapa National Hospital, Zacapa, Guatemala, and 138 seronegative controls for polymorphisms of HLA-B, MHC class I chain-related gene A (MICA), and the Tumor Necrosis Factor-a (TNF-a) promoter region. The frequency of HLA- B35 was significantly increased in the cardiac Chagas patients $(\mathrm{Pc}<0.003, \mathrm{OR}=5.50,95 \% \mathrm{CI}=2.31-13.11)$. Although there was no association between MICA, TNF-a promoter region polymorphisms and the disease, the increased risk for the individuals who had both HLAB35 and MICA-A5 (delta odds ratio; ORB35/A5 -1=9.80) was higher than the sum of the increased risks for either HLAB35 (ORB35 $-1=2.78$ ) or MICA-A5 single positive (ORA5 -1=0.08) individuals, indicating that the effects of the two alleles on susceptibility were synergistic.

Key words: Chagas disease, Trypanosoma cruzi, HLA-B, MHC class I chain-related gene A (MICA), sequence specific oligonucleotide probe (SSOP) 